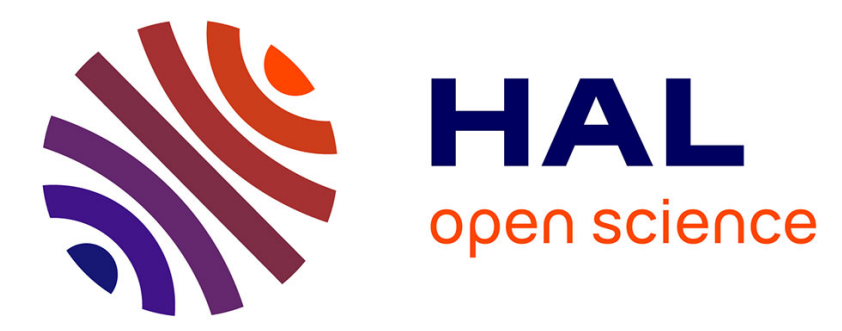

\title{
Self-powered ultra-low power DC-DC converter for RF energy harvesting
}

\author{
Salah-Eddine Adami, Vlad Marian, Nicolas Degrenne, Christian Vollaire, \\ Bruno Allard, François Costa
}

\section{- To cite this version:}

Salah-Eddine Adami, Vlad Marian, Nicolas Degrenne, Christian Vollaire, Bruno Allard, et al.. Selfpowered ultra-low power DC-DC converter for RF energy harvesting. FTFC, Jun 2012, Paris, France. pp.CD, 10.1109/FTFC.2012.6231746 . hal-00719861

\section{HAL Id: hal-00719861 \\ https://hal.science/hal-00719861}

Submitted on 21 Jul 2012

HAL is a multi-disciplinary open access archive for the deposit and dissemination of scientific research documents, whether they are published or not. The documents may come from teaching and research institutions in France or abroad, or from public or private research centers.
L'archive ouverte pluridisciplinaire HAL, est destinée au dépôt et à la diffusion de documents scientifiques de niveau recherche, publiés ou non, émanant des établissements d'enseignement et de recherche français ou étrangers, des laboratoires publics ou privés. 


\section{Self-Powered Ultra-low Power DC-DC Converter for RF Energy Harvesting}

\author{
Salah-Eddine Adami, Vlad Marian, Nicolas Degrenne, \\ Christian Vollaire, Bruno Allard \\ University of Lyon, Ecole Centrale de Lyon \\ Ampere Laboratory \\ Lyon, France \\ salah-eddine.adami@ec-lyon.fr
}

\author{
François Costa \\ University Paris Est Créteil \\ SATIE Lab, ENS de Cachan \\ Cachan, France
}

\begin{abstract}
In this paper, an autonomous low voltage and ultralow power DC-DC converter is presented. This novel topology is inspired from the classical Armstrong oscillator structure. In addition to be self-powered and autonomous, this converter is suitable for high-impedance sources. Theoretical and simulationbased optimizations are used in order to design the converter. A fabricated prototype is tested. It harvests RF energy from a low power rectenna (rectifying antenna). High output voltage and good performances are achieved in the range of $4 \mu \mathrm{W}$ to $1 \mathrm{~mW}$ of input power.
\end{abstract}

Keywords- ultra-low power, low voltage, self-oscillating DC-DC converter, $R F$ energy harvesting, rectenna.

\section{INTRODUCTION}

Nowadays, energy harvesting is an emerging topic that electronic researchers are increasingly interested in. It is based on collecting very small amounts of energy from the environment using small scale transducers. The harvested energy is used in order to feed low power circuits such as Wireless Sensor Nodes (WSNs). There are various sources for energy harvesting [1]: solar, organic, vibration, thermal, nearfield electromagnetic and far-field electromagnetic (or RadioFrequency RF). Most energy harvesting transducers deliver a very low voltage (below $1 \mathrm{~V}$ ) and a very low power (below $1 \mathrm{~mW})$. A voltage level of few volts is essential in order to supply conventional electronic circuits (wireless sensors in particular). Voltage step-up can be achieved with power electronics, but again, conventional commercial DC/DC converters need at least $1 \mathrm{~V}$ of input voltage and require a minimum power in order to start-up functioning. Specific new circuit architectures are therefore necessary. For this purpose, various topologies of low voltage and low power DC-DC converters have emerged these last years from both industrial and academic research. Fig. 1 and Tab. I show an overview of those converters.

Most low-voltage and low-power converters need an external power source (A on Fig. 1). It can be either the external output rechargeable battery or a storage capacitor charged to a sufficient level. In [2] a DC/DC boost converter powered by the external output battery is presented. It harvests low RF energy $(>10 \mu \mathrm{W})$. Another ultra-low power boost converter is presented in [3]; output capacitor has to be charged to $650 \mathrm{mV}$ in order to supply the control circuit.

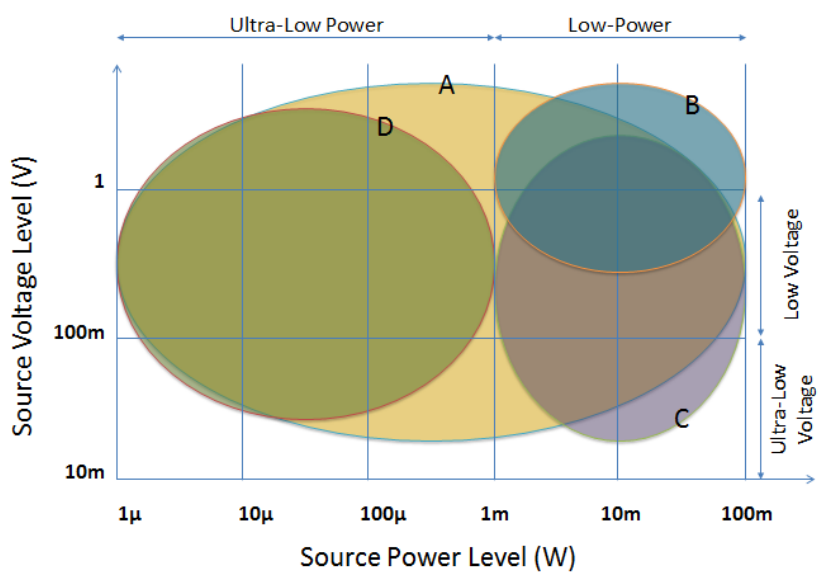

Figure 1. State of the art of low voltage and low power converters

TABLE I. LOW VOLTAGE AND LOW POWER CONVERTERS CATEGORIES

\begin{tabular}{|c|c|c|c|}
\hline \multicolumn{2}{|c|}{$\begin{array}{l}\text { Battery-Powered } \\
\text { Converters }\end{array}$} & \multicolumn{2}{|r|}{ Battery-less Converters } \\
\hline \multirow[t]{3}{*}{$\mathrm{A}$} & \multirow[t]{3}{*}{$\begin{array}{l}\text { Wide range } \\
\text { of input } \\
\text { voltage and } \\
\text { power [2-3] }\end{array}$} & B & $\begin{array}{l}\text { Special low voltage integrated circuit based on: } \\
\text { - Sub-threshold CMOS design [4] } \\
\text { - } \quad \text { Silicon-On-Insulator (SOI) technology } \\
\quad[5]\end{array}$ \\
\hline & & $\mathrm{C}$ & $\begin{array}{l}\text { Classical Armstrong-oscillator-based converters } \\
\text { (ultra-low voltage) [6-9] }\end{array}$ \\
\hline & & $\mathrm{D}$ & $\begin{array}{l}\text { Novel Armstrong-oscillator-based converter } \\
\text { (ultra-low power) [this work] }\end{array}$ \\
\hline
\end{tabular}

Self-powered converter topologies (B, C and D on Fig. 1) are more adapted for autonomous WSNs. Unlike a battery system in which batteries have limited charge/discharge cycles, a battery-less system does not require any maintenance. Furthermore, energy harvesting systems do not contribute to a good battery health because of the non-regulated available energy for most sources. Batteries are space consuming and they take a large part of the system size. For these reasons, a self-powered system is more reliable and offers more application opportunities. 
There are two major types of self-powered converters. First type is based on special low power integrated circuit techniques, i.e. the use of sub-threshold design [4] and also the use of low-power and low-voltage fabrication technologies such as Silicon-On-Insulator (SOI) [5].

The second category of self-powered converter is based on the use of self-oscillating circuits. Armstrong oscillator [6-9] is commonly used in this field. Major benefit of such structure is ultra-low input voltage and also high voltage stepping-up abilities. Oscillating circuits are often used as a start-up part of a principal converter because of the need of an external regulated voltage. Most self-oscillating circuits operate for milli-watts power levels. In [7] a $100 \mathrm{~mW}$ boost converter using the Armstrong oscillator as a start-up stage is presented. Similar topologies are presented in [8-9] for $17 \mathrm{~mW}$ and $1 \mathrm{~mW}$ respectively.

The aim of this article is to present a novel topology of selfoscillating converter that is suitable for ultra-low power applications (several $\mu \mathrm{W}$ to $1 \mathrm{~mW}$ ). This converter is suitable in particular for RF energy harvesting. For such system, the energy source which is a rectenna has a large internal impedance (several $\mathrm{k} \Omega$ ), resulting in ultra-low available current.

Rectennas are introduced in part II. The converter topology, the design procedure as well as the performances are presented in part III. In the part IV, the converter is powered by the rectenna in order to evaluate the global performances of the system.

\section{LOW-POWER RECTENNA}

The association of a receiving antenna and an RF-DC rectifier circuit is called a rectenna (rectifying antenna). A rectenna usually operates in the range of UHF (f $>1 \mathrm{GHz}$ ) enabling long range wireless energy transfer with relatively compact antennas.

Rectenna operation principle is illustrated in Fig. 2. The incident RF power is captured by an antenna under the form of a high frequency sine wave. This is then transformed into DC power by the diode-based converter. A HF filter ensures impedance adaptation between the antenna and the diode rectifier around work-frequency $(2.45 \mathrm{GHz})$ for optimal power transfer. The output DC filter smooths the output DC voltage and current by attenuating high frequency harmonics present in the RF signal or generated by the rectification process itself.

In the case of low incident power levels (below $1 \mathrm{~mW}$ ), rectifier is often based on series-mounted diode. This structure offers the best compromise between DC output voltage level and conversion efficiency at those low incident power levels [10]. Furthermore, zero bias Schottky diodes are often used in this case due to their low threshold voltage (around $150 \mathrm{mV}$ ) and their low junction capacitance $(0.18 \mathrm{pF})$ [11].

A prototype of a single series-mounted diode rectenna was fabricated on a low-cost $1.6 \mathrm{~mm}$ FR4 substrate. In order to evaluate the rectenna output characteristic, the fabricated prototype was tested under wide range of input RF power and output load resistance. RF power is directly supplied by a power source through a SMA cable. Current-Voltage (I-V) and Efficiency-Load ( $\mathrm{n}-\mathrm{R})$ characteristics are shown in Fig. 3.

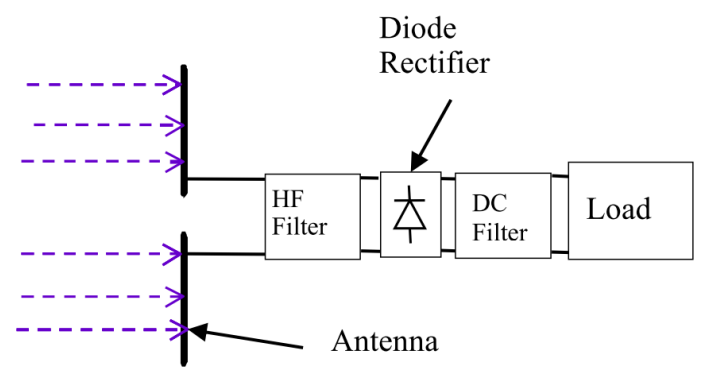

Figure 2. Block diagram of a rectenna circuit
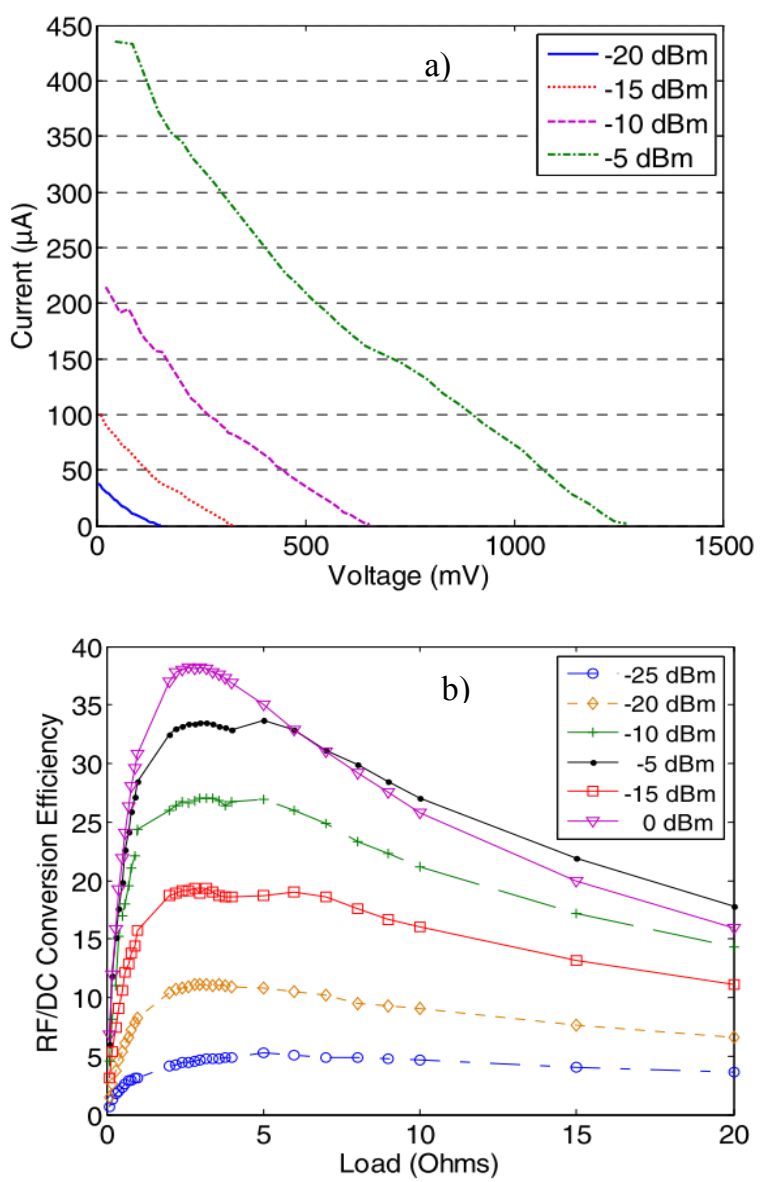

Figure 3. Series-mounted rectenna output characteristic: a) Current-Voltage, b) Efficiency-Load

I-V characteristic are almost parallel straight lines. In addition, conversion efficiency is maximal for a specific fixed output load value. Therefore, rectenna output DC model is a voltage source in series with its internal impedance. This internal impedance is equal to the optimal load value $(2.4 \mathrm{k} \Omega$ in this case). For a $-15 \mathrm{dBm}(30 \mu \mathrm{W})$ level of injected RF power, output open-circuit voltage is equal to $300 \mathrm{mV}$. In this case, the maximum DC power is around $10 \mu \mathrm{W}$. In order to be able to use this energy, a specific DC-DC converter topology would be needed in order to provide a conventional over $1 \mathrm{~V}$ voltage level. 


\section{SELF-OSCILlATING DC-DC CONVERTER TOPOLOGY}

\section{A. Topology Presentation and Operation}

This converter is inspired from the classical Armstrong oscillator topology [6-9]. In addition to its self-powering capability (neither external energy source nor external control are needed), this converter was optimized in order to accept very high source impedance (up to several k $\Omega$ ). Fig. 4 shows the converter topology.

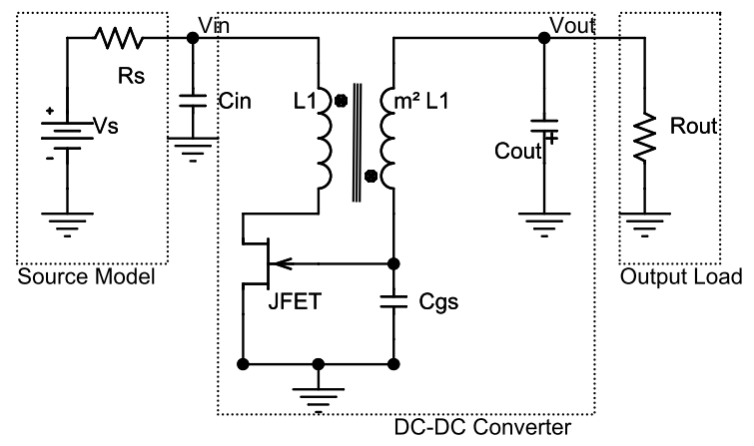

Figure 4. Self-oscillating DC-DC converter circuit

This converter contains three blocks which are essentials for its well-functioning:

- The oscillator: it is composed by the JFET which amplifies the gate's input signal. The oscillator return loop is formed by the two coupled-inductors and by the gate-source capacitor $\mathrm{C}_{\mathrm{gs}}$ (which includes main parasitic capacitors).

- Voltage stepping-up: standard over $1 \mathrm{~V}$ level is obtained from a very low source voltage level (some hundreds of $\mathrm{mV}$ ) via a high step-up ratio transformer.

- The rectifier: in order to rectify JFET's gate oscillating voltage, the gate-source PN junction of the transistor is used. When the voltage of the gate becomes superior to the diode threshold voltage, the diode is turned $\mathrm{ON}$ and the circuit supplies the output load.

When the converter is connected to energy source, the current increases in the primary winding; the secondary winding applies then a positive voltage on the normally-on Nchannel JFET's gate. The gate-source PN junction of the JFET is conducting, and the output capacitor is charged with a negative voltage. The output voltage is therefore negative. When the primary current reaches saturation, the voltage across the primary winding cancels and the negative voltage of the output capacitor is applied on the gate of the JFET pinching it off. The current in the primary winding decreases and a negative voltage is applied by the secondary winding on the gate of the JFET, which leads to its switching off. This peak voltage that switched off the JFET falls back to zero and the oscillation process starts again.

This circuit topology is very similar to those how are already present in the literature. However, there is a main advantageous of this structure in ultra-low current applications. Classical structure has a Flyback mode of operation, while this topology is based on a Forward mode. Energy is transferred to the output during the on-phase which avoids the collapse of the switch gate voltage oscillations during the off-phase (case of Flyback operation mode).

\section{B. DC-DC Converter Design and optimization}

Theoretical as well as simulation optimizations have been performed. The source is characterized by a low voltage (several hundreds of $\mathrm{mV}$ ) and by a very high internal impedance (several $\mathrm{k} \Omega$ ). Theoretical calculations on oscillations start-up conditions show that in order for the converter to work properly with such low input voltage and such high source impedance, JFET cutoff voltage $V_{p}$ as well as its zero-gate voltage drain current $\mathrm{I}_{\mathrm{DSs}}$ have to be minimized. Furthermore, transformer turn ration is a compromise between efficiency and start-up capability.

Regarding to optimization results, best commercially available JFET is the $\mathrm{J} 201\left(\mathrm{I}_{\mathrm{DSS}}=583 \mu \mathrm{A} ; \mathrm{V}_{\mathrm{p}}=-0.6 \mathrm{~V}\right)$. The optimal transformer turn ratio is around 1:20 (Coilcraft LPR6235-253PMB). The high-frequency transformer model has been established (from $40 \mathrm{~Hz}$ to $1 \mathrm{MHz}$ ) using an impedance meter (Agilent 4294A) and using the model described in [12]. This model includes: serial coils resistances, coupling coefficient and stray capacitances. The DC/DC converter was simulated using Pspice with the parameters indicated in Tab. II.

TABLE II. SIMULATION MODEL PARAMETERS

\begin{tabular}{|c|c|c|c|c|}
\hline & Symbol & description & value & Unit \\
\hline \multirow{3}{*}{ 㫐 } & $\mathrm{I}_{\mathrm{DSS}}$ & Zero-gate voltage drain current & 583 & $\mu \mathrm{A}$ \\
\hline & $V_{p}$ & Gate-source cutoff voltage & -0.6 & $\mathrm{~V}$ \\
\hline & Cgs, Cgd & JFET capacitances & $3 ; 4$ & $\mathrm{pF}$ \\
\hline \multirow{7}{*}{ 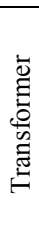 } & L1 & Primary inductance & 23.74 & $\mu \mathrm{H}$ \\
\hline & $\mathrm{m}$ & Turn ratio & $1: 20$ & - \\
\hline & $\mathrm{Cp}$ & Primary stray capacitance & 3.13 & $\mathrm{nF}$ \\
\hline & $\mathrm{Cs}$ & Secondary stray capacitance & 13.9 & $\mathrm{pF}$ \\
\hline & Cps & Prim. to secon. stray capacitance & 50.9 & $\mathrm{pF}$ \\
\hline & RL1 & Primary coil resistance & 155 & $\mathrm{~m} \Omega$ \\
\hline & RL2 & Secondary coil resistance & 54.8 & $\Omega$ \\
\hline
\end{tabular}

\section{Simulation and experimental results}

A prototype was fabricated in order to evaluate the real performances and to make comparison with simulations results. In this first step, the rectenna model $\left(\mathrm{R}_{\mathrm{s}}=2.4 \mathrm{k} \Omega\right)$ is used and the source power is controlled via the voltage source $V_{s}$.

First step of experimental tests consists of varying the output load resistance for a fixed value of the input power. This test shows that maximum output power is reached with a $600 \mathrm{k} \Omega$ load resistance. This is an optimal value that is kept in the following measurement. Afterwards, converter input and output voltages are measured for each value of input power. The simulation results are compared to experimental data. Fig. 5 shows input and output voltages as a function of input power level. Simulation results are close to the experimental data, which proves that simulation model is quite accurate. In addition, the voltage step-up ratio (up to 9) is almost constant over all input voltage range. Fig. 6 shows the efficiency of the converter as a function of input power level.

Converter efficiency reaches a maximum of $25 \%$ for input power levels between $60 \mu \mathrm{W}$ and $200 \mu \mathrm{W}$. For power levels from $5 \mu \mathrm{W}$ to $1 \mathrm{~mW}$, efficiency is between $10 \%$ and $25 \%$. 


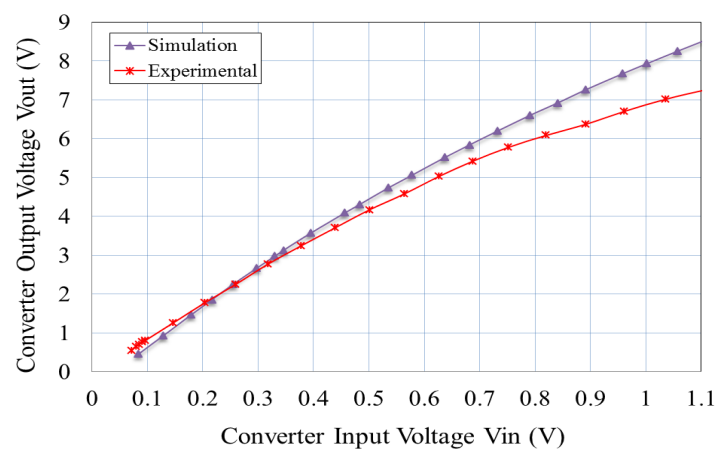

Figure 5. DC-DC converter input and output voltages

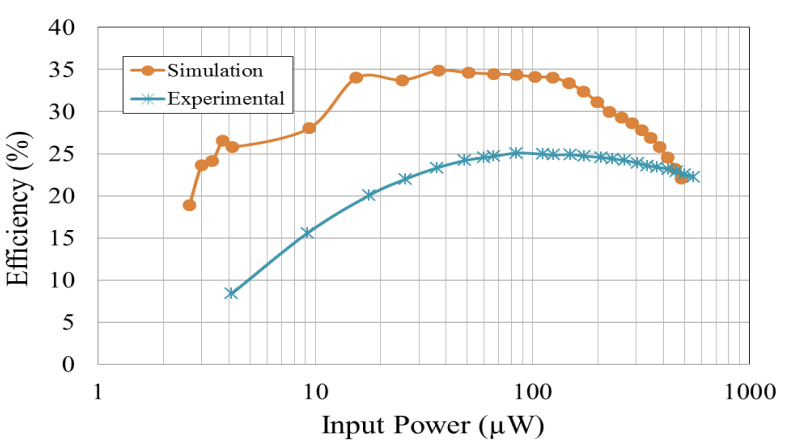

Figure 6. DC-DC converter efficiency vs. input power

Most losses are due to the JFET on-resistance which is high because of the low gate-cutoff voltage $V_{p}$ (the drain-source channel is weakly doped). A low $\mathrm{V}_{\mathrm{p}}$ and a low $\mathrm{I}_{\mathrm{DSs}}$ are essential in order to satisfy the oscillations start-up conditions (for low source voltage and high source impedance). However, this leads to increase losses in the steady state. There is a compromise between start-up capability and steady state efficiency.

\section{SELF-OSCILLATING DC-DC CONVERTER POWERED BY A RECTENNA}

In order to evaluate the global performances, the selfoscillating converter is associated with the previously described rectenna. A power RF signal generator is used to feed the RF$\mathrm{DC}$ rectifier (power signal frequency is $2.45 \mathrm{GHz}$ ).

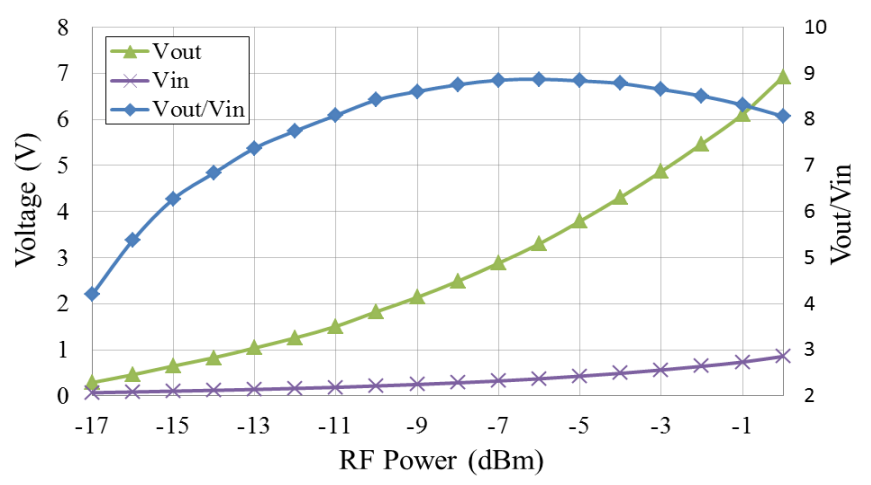

Figure 7. The converter powered by a rectenna: converter input and output voltages Vs. rectenna input power
Input power is varied from $-20 \mathrm{dBm}$ to $0 \mathrm{dBm}$. The external load is equal to the optimal load resistance of $600 \mathrm{k} \Omega$. Fig. 7 shows the converter input and output voltage and the steppingup ratio with respect to the input power at rectenna level.

Whilst input voltage at converter level is under $1 \mathrm{~V}$ for the entire range of input power, the output voltage rises to $7 \mathrm{~V}$ for $0 \mathrm{dBm}$. Furthermore, output voltage is above $1 \mathrm{~V}$ for input power levels higher than $-13 \mathrm{dBm}$.

\section{CONCLUSION}

A self-powered, low voltage and ultra-low power DC-DC converter has been presented in this paper. It is suitable for high-impedances sources which provide ultra-low current. The converter performances were demonstrated using experimental tests. The fabricated prototype harvests low RF power $(4 \mu \mathrm{W}$ $1 \mathrm{~mW}$ ) from a low power rectenna. $25 \%$ efficiency is achieved as well as a high voltage step-up ratio (up to 9). Furthermore, this converter is very compact $\left(<0.5 \mathrm{~cm}^{3}\right)$ and has a very low cost $(<1$ USD for $1 \mathrm{k}$ units), which is suitable for industrial applications. Although it was designed for RF energy harvesting, this converter could be adapted and used with other energy-harvesting transducers.

\section{REFERENCES}

[1] J. M. Conrad, "A survey of energy harvesting sources for embedded systems," in IEEE SoutheastCon 2008, 2008, pp. 442-447.

[2] T. Paing, J. Shin, R. Zane, and Z. Popovic, "Resistor Emulation Approach to Low-Power RF Energy Harvesting," IEEE Transactions on Power Electronics, vol. 23, no. 3, pp. 1494-1501, May. 2008.

[3] E. Carlson, K. Strunz, and B. Otis, "20mV Input Boost Converter for Thermoelectric Energy Harvesting," Symposium A Quarterly Journal In Modern Foreign Literatures, vol. 2, 2009, pp. 162-163.

[4] A. Wang and A. Chandrakasan, "A 180-mV subthreshold FFT processor using a minimum energy design methodology," IEEE Journal of Solid State Circuits, vol. 40, no. 1, pp. 310-319, 2005.

[5] Y. Yoshida, F. Utsunomiya, T. Douseki, "Adaptive-Vth CMOS/SOI DC-DC Converter Scheme for 0.3-V Operation," International SOI Conference, 2006 IEEE , pp.119-120, 2-5 Oct. 2006.

[6] D. Grgić, T. Ungan, M. Kostić, and L.M. Reindl, "Ultra-low input voltage DC-DC converter for micro energy harvesting," PowerMeMs, 2009, pp. 265-268.

[7] J.M. Damaschke, "Design of a low-input-voltage converter for thermoelectric generator," IEEE Transactions on Industry Applications, vol. 33, 1997, pp. 1203-1207.

[8] L. Mateu, M. Pollak, and P. Spies, "Analog Maximum Power Point Circuit Applied to Thermogenerators," iis.fraunhofer.de, pp. 1-4.

[9] M. Pollak, L. Mateu, and P. Spies, "Step-up DC-DC-Converter with coupled inductors for low input voltages," Fraunhofer IIS, 2008.vol. 86 , May. 2011, pp. 625-632.

[10] V. Marian, C. Vollaire, J. Verdier, B. Allard, "Potentials of an Adaptive Rectenna Circuit," Antennas and Wireless Propagation Letters, IEEE, vol.10, pp.1393-1396, 2011.

[11] B. Merabet, F. Costa, H. Takhedmit, C. Vollaire, B. Allard, L. Cirio, O. Picon, "A 2.45-GHz localized elements rectenna," Microwave, Antenna, Propagation and EMC Technologies for Wireless Communications, 2009 3rd IEEE International Symposium on, pp.419-422, 27-29 Oct. 2009.

[12]H. Y. Lu, J. G. Zhu, S. Member, and S. Y. R. Hui, "Experimental Determination of Stray Capacitances in High Frequency Transformers," IEEE Transactions on Power Electronics, vol. 18, no. 5, pp. 1105-1112, 2003 